\title{
Challenges of Renewable Forest Fuels for Green Electricity Market
}

\author{
Teijo Palander ${ }^{1}$, Kalle Kärhä ${ }^{2}$ \\ ${ }^{1}$ Department of Forestry, University of Eastern Finland, Kuopio, Finland \\ ${ }^{2}$ Stora Enso Oyj Metsä, Helsinki, Finland \\ Email: teijo.s.palander@uef.fi, kalle.karha@storaenso.com
}

Received 31 December 2015; accepted 15 February 2016; published 18 February 2016

Copyright (C) 2016 by authors and Scientific Research Publishing Inc.

This work is licensed under the Creative Commons Attribution International License (CC BY). http://creativecommons.org/licenses/by/4.0/

\section{(c) (i) Open Access}

\begin{abstract}
In this study, strategic electricity market scenarios are considered in a grid of Scandinavia. This multiple-objective decision environment includes the allocation of a number of renewable forest fuel procurement chains to a combined heat and power plant in Finland. The decision environment includes also electricity procurement from Sweden and Russia. The environment is further complicated by sequence-dependent operations of the local procurement chains during different periods. Due to the complex nature of the environment, multiple-objective methods cannot be directly used to solve the electricity production problem in a manner that is techno-economically relevant to the forest energy industry. Therefore, local and time-varying parameters were measured in local wood procurement conditions to improve the solution method. Using these measurements the smart decision-support system automatically adjusted the multiple-objective methodology to better describe the combinatorial complexity of the production sector. The properties of this methodology are discussed and three scenarios of how the system works based on local real-world data and optional feed-in tariff of green electricity are presented. The Finnish electricity market is subject to policy decisions regarding green energy production regulations. These decisions should be made on the basis of local techno-economic analysis presented in this study accounting for the effects of forest operations on the electricity production and import.
\end{abstract}

\section{Keywords}

Decision-Support System, Distributed Electricity Production, Feed-In Tariff, Green Electricity, Local Measure, Smart System

\section{Introduction}

A transition from the current fossil fuel- and nuclear-based energy systems into future sustainable energy sys- 
tems requires an increasing use of renewable forest energy sources. In most countries in Europe, forest biomass sources are small compared to the European energy balance [1]. However in Finland, forest biomass provides a potential of 50 percent annual increase of wood-based fuels. Therefore, the development of sustainable energy systems and technologies involves a combination of primary energy sources from forests to energy plants together with residual sources such as industrial wood wastes [2]. In Finland, the forest energy systems are typically based on forest fuel procurement measures as an important part of such technology [2]. In Europe, the design of biomass energy systems including 4th Generation District Heating Technologies and Systems is described in a number of recent studies including [3]-[6].

Forest energy sources offer near-zero net $\mathrm{CO}_{2}$ emissions. As a response to climate change [7], the Finnish government has proposed that renewable energy production should account for 38 percent of the national total by 2020, and believes that the utilization of forest fuels in energy production is a promising approach to accomplish this goal [8]-[10]. In Finland, 8.7 million solid $\mathrm{m}^{3}$ of forest chips were used to generate 17TWh of energy in 2013 [9] [11]. There are currently targets to increase the annual use of forest chips to 13.5 million solid $\mathrm{m}^{3}$ per year (25TWh) by 2020 [8]-[10]. These targets presuppose that the delivery of forest chips to the energy-production sector should be doubled compared with the current delivery volume. Therefore, the change to forest energy systems is to be regarded as a technological challenge. The important point is that this will require significant changes in existing local processes of forest organizations; and such a change is complicated by the time-dependent and sequence-dependent operations involved in the forest fuel procurement of the combined heat and power (CHP) plants.

In Finland, local processes of large wood procurement organizations have been decentralized [12]. The characteristics of decentralized wood procurement from local forests to the plants are as follows:

- Long tradition for optimization of wood procurement from wood resource inventories to spatially separated saw-, pulp- and energy plants;

- Relatively small average volume of stands $\left(\mathrm{m}^{3}\right)$ and long terrain transport distances because of the big amount of small non-industrial private forest holdings;

- Big share of thinnings in the cutting volumes and interest in environmental aspects;

- Good quality of cutting and minimum losses of timber;

- Good roads for trucks and waterways for bundle floating and railways;

- Good know-how in applying the cut-to-length logging method and building up suitable machinery;

- Advanced logistic systems, including computerized planning and control systems of work operations designed to support cut-to-length method.

The CHP technology is defined to mean heat produced by combustion of fuel to drive a steam-based generator, and power in the form of electrical energy [9]. In this study, it is assumed that both forms of energy can be used by the plant that produces them, or sells to other customers, including the local pulp mill and national electrical grid. On the other hand, the CHP technology is referred to the so-called 4th Generation Technology, because it is an integrated part of smart energy systems (i.e. integrated smart electricity and thermal grids) [6]. A typical Finnish CHP plant purchases less than 5 percent of its energy needs from the national electrical grid and can sell power about 40 percent to the grid [13]. So far, this has not been economically possible, but Finnish government will aim to increase electricity production from ("green") wood-based fuels [8] [13]. However, the easy availability of peat biomass means that about 40 percent of the energy generated by CHP plants is provided by burning peat [2]. It is not a renewable fuel because it regenerates too slowly. Therefore, reducing share of peat in the electricity production is important to increasing burning renewable wood-based fuels. Figure 1 shows an illustrative example about CHP's energy fuel mixture in which the volume of the peat fuel is lower than the volume of the wood-based fuels [2].

Finland expects to achieve its "green" electricity target through the implementation of national policy measures [8] [14]-[16]. According to Palander [9], the key principle of the Finnish energy taxation legislation is that all wood-based fuels consumed in the production of electricity are exempt from the tax, whereas the fuels consumed in the production of heat are subject to the tax. When the same plant can produce both electricity and heat, the fuels used by the plant for these two purposes are considered separately for calculating the taxes. In this study, constraints of smart system are going to be used to divide the wood-based fuels for heat and electricity production. Electricity market prices have changed in recent years, which make it important to produce and sell electricity optimally because this is an important factor in determining CHP plant's profitability. Finland supports the sales price of green electricity from CHP plants so that the market price will remain constant and the- 


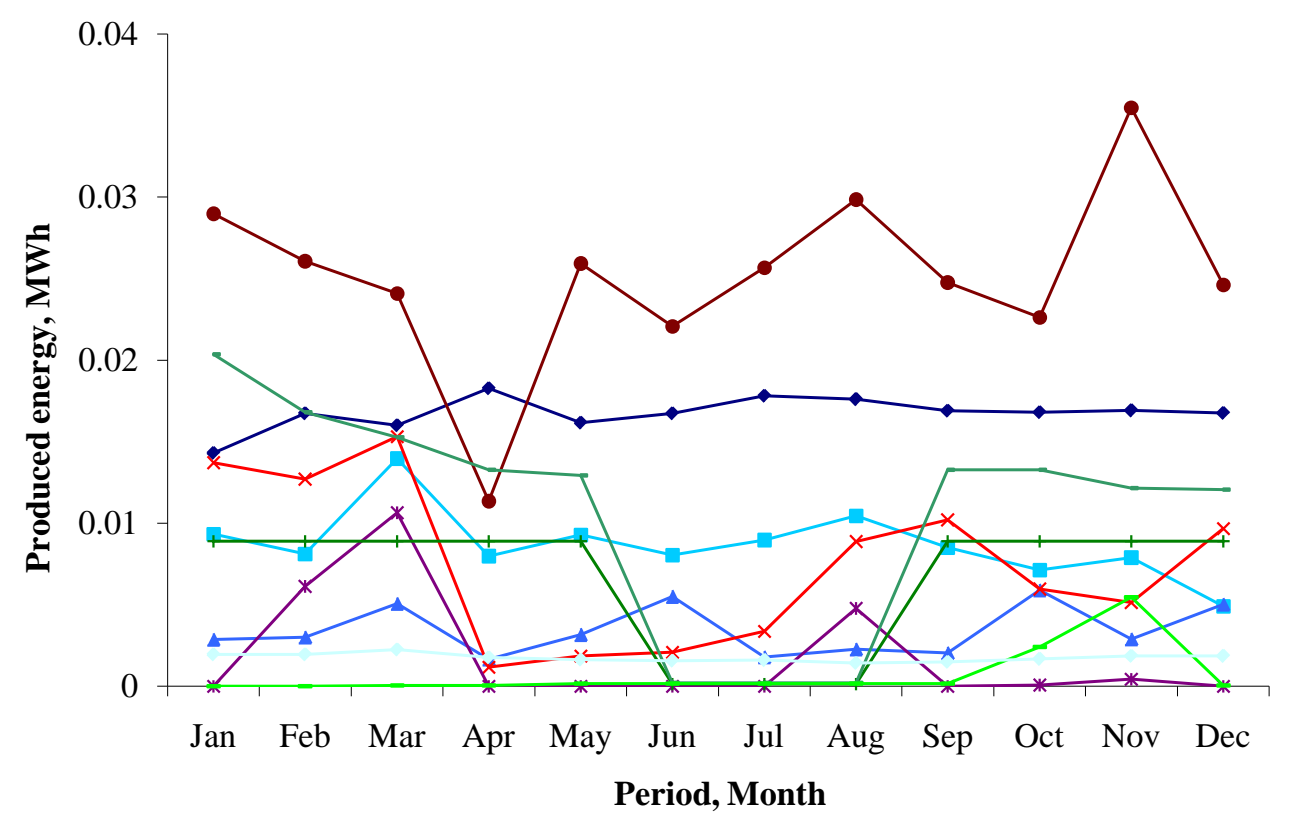

$\longrightarrow$ Liquefied natural gas
$\rightarrow$ Mill wood (purchased)
$\rightarrow$ Coal
$\longrightarrow$ Forest chips
$\longleftarrow$ Forest wood (below-ground)

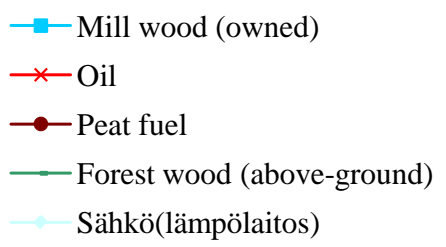

Figure 1. Strategic plan of CHP plant for monthly fuel procurement schedule (as produced energy), $\mathrm{MWh} /$ month [2].

reby encouraging the decentralized production of electricity into a district's electrical network. This price driver is a feed-in tariff for wood-based fuels, which guarantees sales of electricity so as to give producers more confidence in its production. The size of this tariff is 6.9€/MWh.

The cost-efficient consumption of available fuels is also vitally important to the CHP plant [2]. Thus, procurement decisions for forest fuels play a key role in achieving this economical goal. In Finland, local wood procurement conditions vary a lot [12]. Therefore, the cost-efficient procurement process can only be reached by using accurate forest information provided by local planning procedures. In future, the planning systems to be efficient in decision making, they are based on the smart and automatic methodology for solving the local problem at hand. The earliest continuous-time formulations for solving the linear problem of scheduling wood procurement from local forests to plants were presented by Palander [12]. Decision-making systems and a review of the various computerized techniques for scheduling local wood procurement as an energy flow have also been published [2] [9] [10] [17]. In this study, available decision alternatives are assumed to be defined by means of multiple-objective mathematical methods [9] [10] [18]-[21]. However, there has been little research about the smart solution of this energy flow problem in local wood procurement conditions.

The present paper is focused on the development of the smart decision support methodology to support decentralized green electricity production in local wood procurement conditions. According to Lund et al. 2014, the planning process in 4th Generation District Heating Technologies and Systems is a change from the current heat and power sector planning to integrated resource planning and energy system planning [6]. In the context of this study, decision makers need to facilitate a planning procedure where the renewable fuel supply side is synchronized with the electricity demand side in such a way that the increasing proportion of local systems is integrated by a techno-economical way in the national energy system. This requires multiple-objective decisionmaking in a smart grid, but how it is possible to optimize a local multiple-objective model with possibly conflicting decision-making principles (e.g., reducing fuel procurement costs, maximizing revenues, minimizing looses). The problem studied is based on long-term scheduling of electricity production and import, where the 
green electricity is provided by the CHP's production and procurement operations. The energy-flow model of Palander \& Hietanen [22] was developed to describe this planning problem (Figure 2). In Finland, the decentralized electricity production from CHP plants is expected to increase by more than 25 percent by 2050 [23]. Further, improvement in industrial energy efficiency (20 percent) by 2020 is expected to increase electricity production 8 percent by 2050 [13]. In addition to generation of more electricity with heat, there are many other ways to improve energy efficiency, such as improvements in the local procurement systems of wood-based fuels (i.e. minimizing loses); in this sense, improvements result from the efficient technologies used in the local fuel supply systems.

In this study, it is assumed that a high energy efficiency of wood-based fuels for the electricity production can be achieved by using the right mixture of fuels. It is also assumed that local delivering problems of this mixture can be avoided by using a smart decision-support methodology. Therefore, our main focus was on the tests of smart solution methodology. To adjust a production plan to the changed decision environment, three local electricity production scenarios are compared for the consumption of forest fuels based on Finland's plans to decrease the import of Swedish and Russian electricity. The production scenarios were considered for one CHP plant. The smart solution methodology was developed in such a way that it could be easily expanded to include additional CHP plants and their local restrictions simply by modifying the production model's database. Because the strategic planning horizon for such facilities is typically annual, with a monthly procurement schedule, the analysis was performed for a 12-month period, with iterations at 1-month intervals.

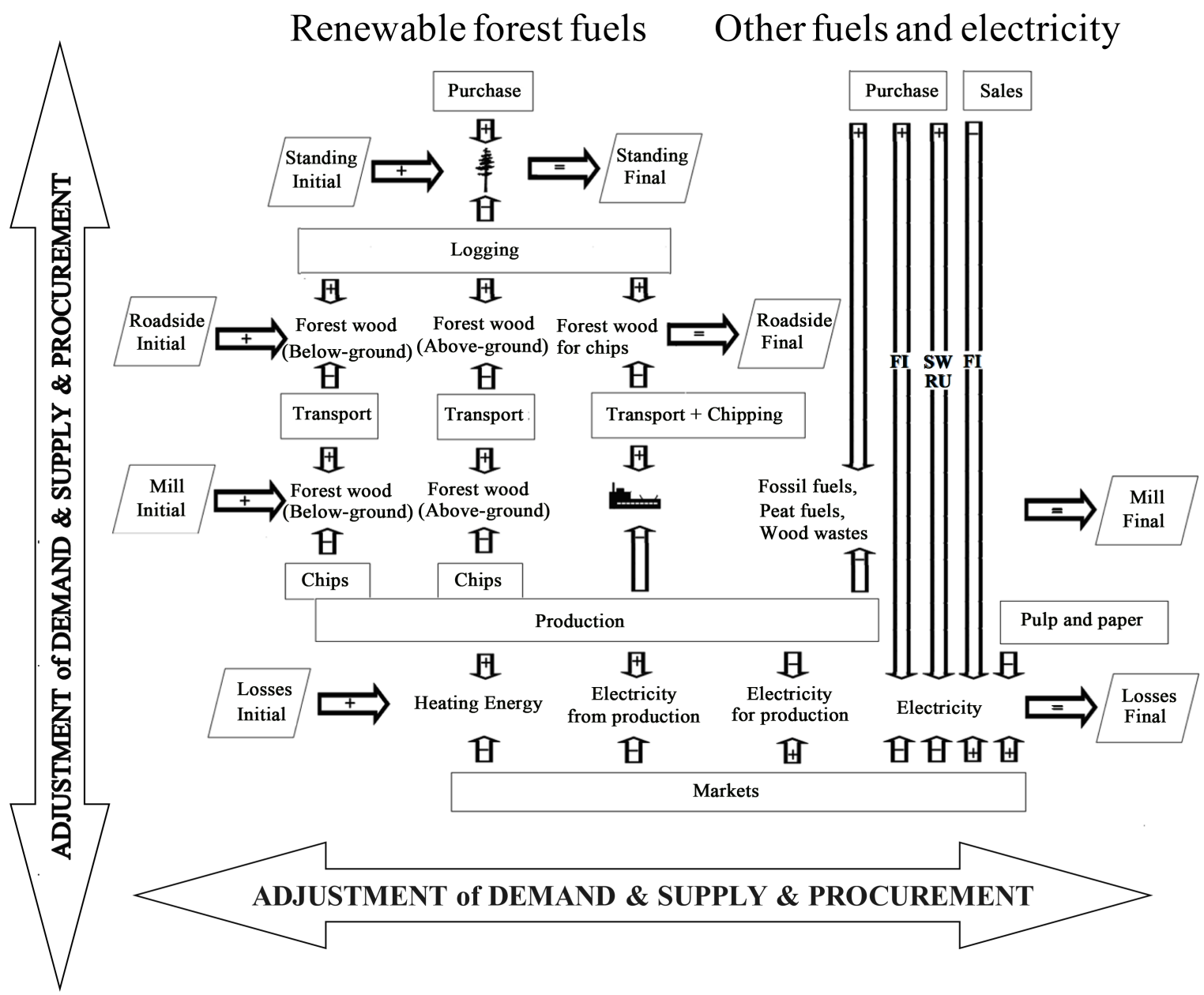

Figure 2. Dynamics of energy-resource inventories for electricity production: Vertical arrows represent sequence-dependent effects for the system; horizontal arrows represent time-dependent effects for the system. Arrows labeled with + represent inputs to a component of the system; arrows labeled with-represent withdrawals from a component. FI = Finland, RU = Russia, SW = Sweden. 


\section{Methodology and Materials}

The optimal operations of the electricity production and the fuel procurement were solved by using developed decision-support system. As mentioned, the smart system will greatly facilitate a planning process, where the local energy supply side is synchronized with the national energy demand side [6]. Anyway, the planning process needs to enable an analysis of changes in operational inventories, mixtures and transaction costs of decision-making parties. In Finland, this requires group decision making systems, where the wood procurement companies are given analytical power in their collaboration with the existing electricity supply companies and large forest industry companies [12] [17]. Figure 3 illustrates a strategic planning procedure of decentralized wood procurement organization. Coordination of forest fuel procurement and electricity production is entailed by the automatic implementation of measures for local changes. They also facilitated collaboration between the local decision makers.

Palander \& Vesa [2] have described how a procurement organization obtain fuel mixtures and construct optimal procurement schedules in a local decision environment. On the other hand, Palander [9] [10] has described how a CHP plant obtains mixtures of electricity and constructs optimal strategic production schedules. In this study, the illustrative local planning procedure allows a combined assessment of the impacts for the decentralized electricity production of including the changes in the consumption of forest fuels and import of fossil- and nuclear-based electricity.

According to Palander [9], in a large-scale and long-term strategic planning problem there is a sufficiently large supply area and a sufficiently long planning horizon that delivery deadlines are unlikely to be missed and other, more important, measurements can be included in the dynamic optimization methodology, such as certain energy flows, intermediate storage times, and transition times. These local measurements are crucial components of the optimization model in the decentralized electricity production, in which obtaining an electricitysales mixture happens during different wood procurement periods and depends on the electricity import. The multiple objective model of Palander [10] can be further developed and converted into software to solve this planning problem. In mathematical terms, the goal programming model was described using the following objective function:

$$
\text { Minimize } Z=w_{1} D_{1}+w_{2} D_{2}+w_{3} D_{3}+w_{4} D_{4}+w_{5} D_{5}+w_{6} D_{6}
$$

where $Z$ is the optimum weighted sum of $D_{g}$, which represents the deviations $(€)$ above and below the decision-maker goals, the parameter $w_{g}$ is a positive weight that reflects the decision-maker's preferences regarding to the relative importance of each objective, and $G$ is the number deviations of decision-maker goals $(1, \ldots, g, \ldots, 6)$. Equation (1) was subjected to fifty-seven local restrictions by using the local parameters of the smart system.

System's test series were run based on real-life data from the CHP plant [9] [10]. To adjust a production plan

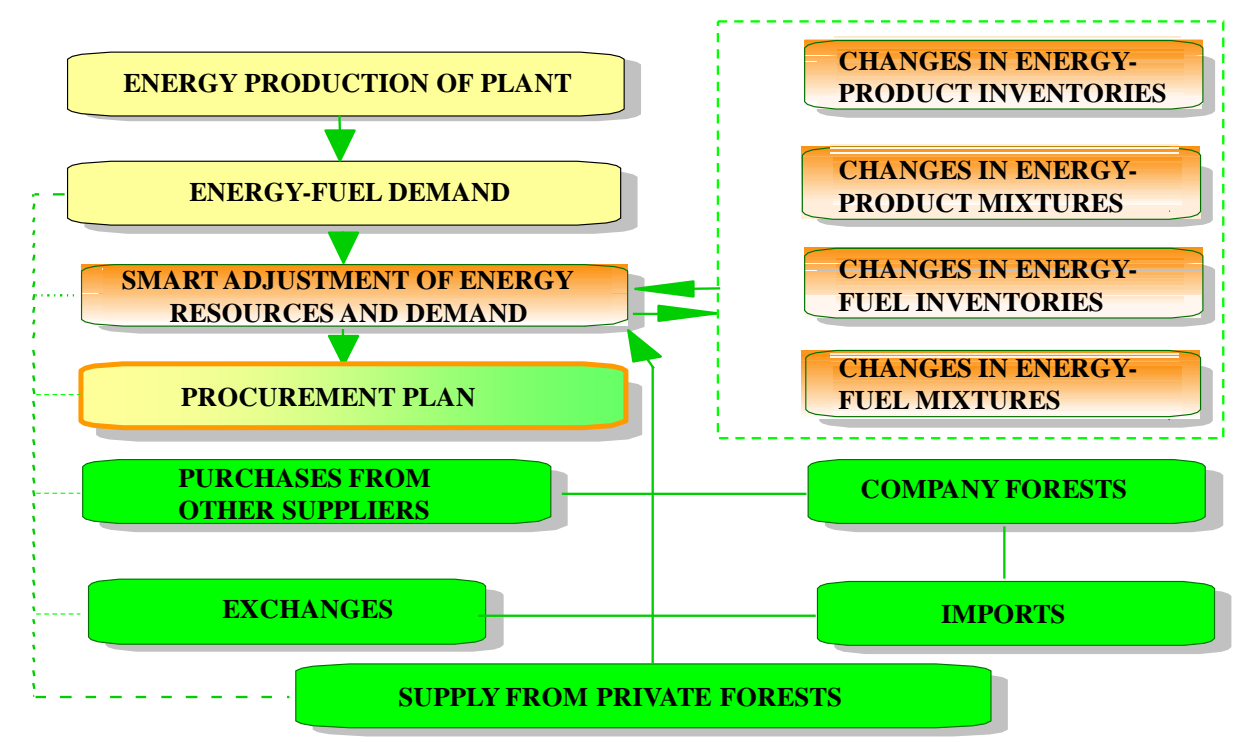

Figure 3. Planning procedure of decentralized wood procurement organization. 
to the changed decision environment, three local scenarios are compared for the consumption of forest fuels based on Finland's plans to decrease the import of Swedish and Russian electricity:

1) Scenario A1: 100 percent to represent the current baseline without feed-in tariff (12 756GWh/year),

2) Scenario A2: 41 percent to represent an optimal system adaptation on a decrease to $0.41 \times$ the baseline value with feed-in tariff (5 205GWh/year), and

3) Scenario A3: zero percent to represent a case without the electricity import with feed-in tariff.

The optimization run of the model was performed on an old desktop computer (2393 MHz $\times 86$ processor) with 4 GB RAM running the Windows XP Professional operating system. The results of this study can be compared to the results of the previous studies [9] [10], because the same computer and software were used. The scheduling algorithm was new and it was implemented using the $\mathrm{C}$ programming language. The automatic database operations of the smart system was created using Microsoft Visual Basic software from version 6.0 of the Microsoft Visual Studio suite. The optimization used version 5.0 of the Lindo API software

(http://www.lindo.com/index.php?option=com_content\&view=article\&id=1\&), with its standard settings, as the linear programming solver. In addition to the automatic smart operations, the program was designed to adapt the model automatically to changing decision environments simply by changing the parameter values for each of the local parameters.

The research area comprised the operating municipalities in southern Finland. The municipalities formed nine procurement areas, which were used to represent the wood procurement teams around CHP plant in Heinola (Figure 4). The map shows new data elements that illustrate electricity imports of Finland. Total capacity of Finnish grid was 5100 MWh for daily electricity import from Estonia, Sweden and Russia [24].

\section{Results and Discussion}

The planning procedure demonstrated that there can be an optimal solution to the electricity production problem, with models' total processing time of 212 - 602 seconds and the total number of multiple-objective linear programming iterations of 354 - 860. We developed the solution methodology of the previous studies by [9] [10]. Actually, the smart methodology solved the adjusted model automatically within a few minutes of computational time using a standard desktop computer. The resulting ranges of CHPs' minimum revenues (a decision object-

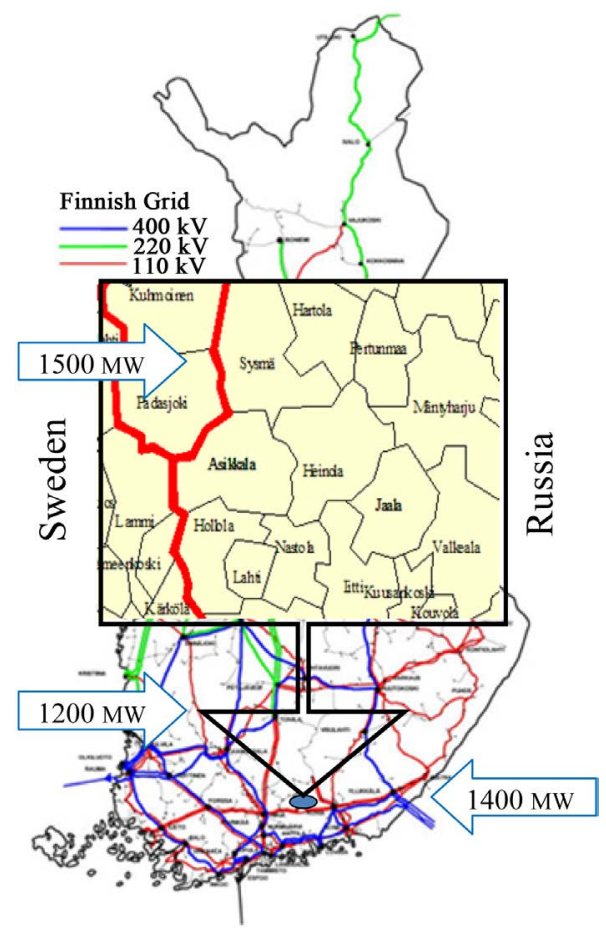

Figure 4. Research area and CHP plant locate in electrical grid of Finland, which is illustrated on the map. 
tive) increased from $€ 49$ million, at a high purchase rate of Russian and Swedish electricity (100 percent, 12,756 GWh), to $€ 389$ million with an optimum purchase rate of Russian and Swedish electricity (41 percent, 5205 GWh) (Table 1). As the method of the previous studies [9] [10], the methodology of this study guaranteed a globally optimal solution within a realistic range of values for the objectives. Further, the results are accordance with Pareto-optimality theory [25], and the Pareto frontier was useful in simulations of electricity production: by restricting attention to the set of choices that are Pareto-efficient, a manager can make trade-offs within a nondominated objective set rather than considering the full range of the system parameters [9]. The software also performed well, although the model could undoubtedly be improved by improving the parameterization of the energy-flow functions that describes the electricity production (Figure 2).

The objective values were reasonable based on the national electricity import and production data of Finland [24]. Including the feed-in tariff revenues for green electricity production increased the total revenues from the energy products, while also decreasing the total fuel procurement costs of electricity products for scheduled production and sales. However, these results depend on set goals by the managers, which must be noted in interpretation of the results. Anyway, bundling the national electricity production targets and local forest fuel procurement measurements together seems to be an interesting opportunity for better collaboration and coordination on decentralized electricity production. In this study, the scenario A2 was more relevant than others in regard to the local parameters of the smart system.

Particular attention is given to describing the local parameter that measured a forest technology rate of the wood procurement machinery in a local forest area. The relevance of the forest technology rate was considered by analyzing CHP's profitability for feasible green electricity production (Table 2). In theory, the objective values were reasonable based on the available forest fuel procurement data, which was used as inputs for the model. However, including the potential technology rates for green electricity production revealed infeasibilities in the scenarios' decision alternatives. This sensitivity analysis also confirms that the scenario A2 is an efficient solution to the electricity production problem. Table 2 shows that in the free adaptation alternative, in theory, larger forest technology rate would increase CHP's profitability due to the green energy production. However, it is irrelevant to increase the technology rate more than 30 percent in forest infrastructure of Finland during the 1-year decision horizon. Therefore, managers must prefer to implement the decision alternative that increases the technology rate by maximum of 30 percent, while decreasing theoretical maximum profitability by 1.54 percent in Scenario A2.

To clarify the differences between the electricity markets in the three scenarios, the energy flows were summarized from different energy-fuel mixtures for the 1-year decision horizon (Figure 5). Increasing the electricity

Table 1. Ranges of three objective values for globally optimal non-dominated decision alternatives for electricity production in Finland: I = Increase limit, D = Decrease limit; A1, A2, and A3 are the scenarios of Finnish electricity supply chains with Russian and Swedish electricity grids that include electricity purchase rates of zero percent, 41 percent (5205 GWh/year), and 100 percent (12 $756 \mathrm{GWh} /$ year), respectively.

\begin{tabular}{|c|c|c|c|c|c|c|c|c|c|c|}
\hline \multicolumn{4}{|c|}{ Total procurement costs of Finnish Grid } & \multicolumn{3}{|c|}{ CHPs' revenues } & \multicolumn{4}{|c|}{ Total loss costs of Finnish Grid } \\
\hline Scenario & I, Million $€$ & Goal, Million $€$ & D, Million $€$ & I, Million $€$ & Goal, Million $€ \mathrm{D}$ & D, Million $€$ & I, Million $€$ & Goal, & Million $€ \mathrm{D}$, & , Million $€$ \\
\hline A1 & $\infty$ & 5116 & 5092 & 708 & 389 & 641 & 133.4 & & 2.5 & 0.4 \\
\hline A2 & $\infty$ & 5116 & 5070 & 487 & 389 & 389 & 129.2 & & 2.5 & 1.1 \\
\hline A3 & $\infty$ & 5116 & 5238 & 708 & 389 & 49 & 143.9 & & 2.5 & 0 \\
\hline
\end{tabular}

Table 2. Analyses of CHP's profitability for feasible green electricity production. Electricity import from Russia (GWh) is replaced by adjusted energy-wood harvesting volumes $\left(\mathrm{m}^{3}\right)$. Basic = maximum profitability.

\begin{tabular}{ccccccc}
\hline & \multicolumn{5}{c}{ Potential Technology Rate Increases Energy Wood Harvesting by 2014 (EWH) } \\
\cline { 2 - 6 } Electricity Import from Russia by 2014 (IR) & $10 *$ EWH & $30 *$ EWH & $50 *$ EWH & $70 *$ EWH & $90 *$ EWH & FREE \\
\hline A1 $(0.0 *$ IR) & Infeasible & Infeasible & -2.35 & -1.48 & -0.99 & - \\
A2 $(0.4 *$ IR) & -2.38 & -1.54 & -1.09 & -0.82 & -0.68 & Basic \\
A3 $(1.0 *$ IR) & Infeasible & Infeasible & -2.59 & -1.72 & -1.24 & - \\
\hline
\end{tabular}




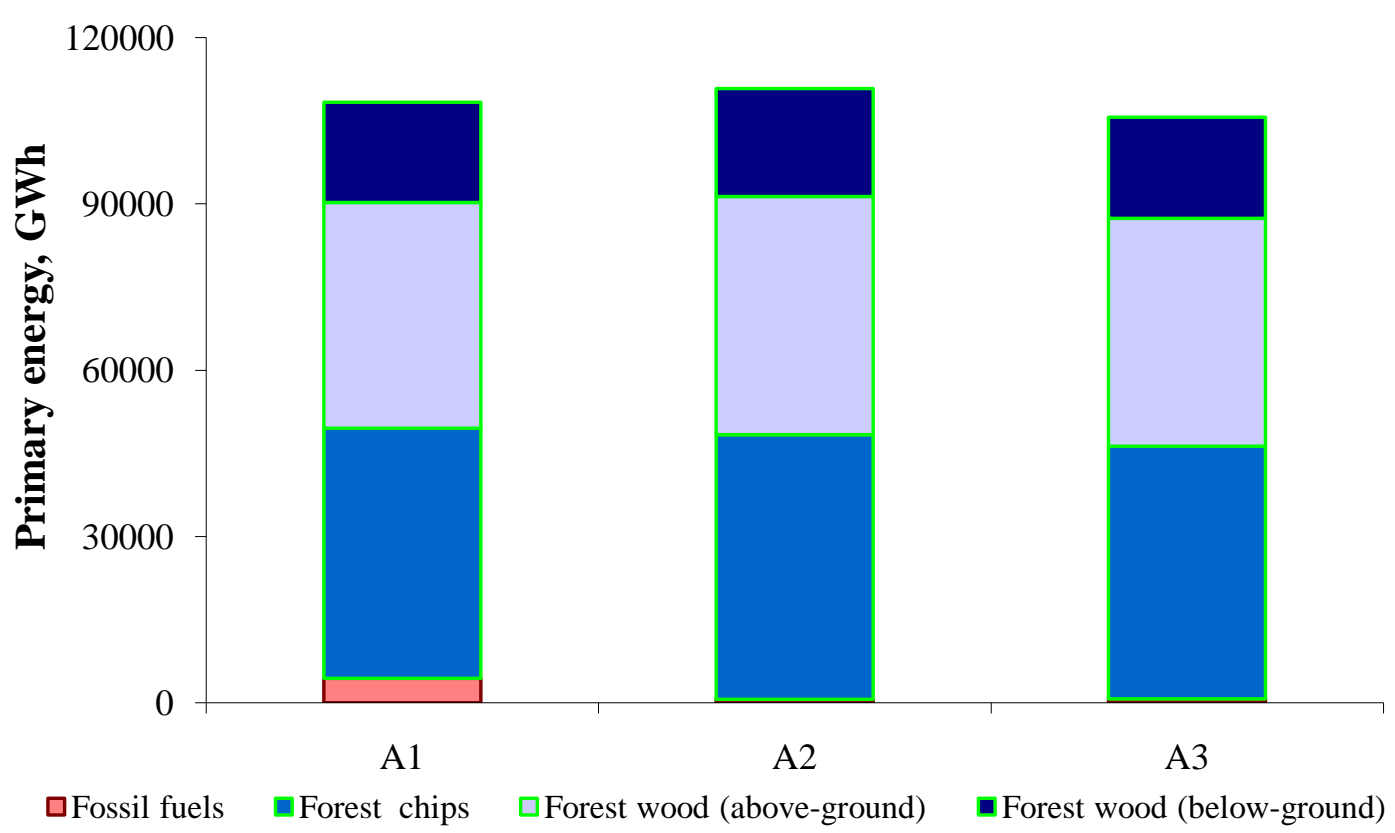

Figure 5. Changes in the fossil and forest fuel procurement volumes: A1, A2, and A3, the scenarios of energy supply chains with Russian and Swedish electricity grids that include electricity purchase rates of zero percent, 41 percent (5205 GWh/year), and 100 percent (12,756 GWh/year), respectively.

purchase rate from Russia and Sweden affected the consumption levels of the fossil (coal and oil) and forest fuels. For example, the annual mean fossil procurement level increased by 85 percent in the scenarios, when the purchase rate from Russia and Sweden increased from zero percent to 100 percent. At the same time, the optimum green electricity production in the A2 scenario decreased the fossil fuel procurement level by 87 percent. These results were consistent with the previous results that the differences between the procurement levels of the various forest fuels that resulted from inclusion of the electricity import targets into the optimization model must also result from local forest technology rates [9]. The procurement of total forest fuel volumes accounted for by all the forest wood components increased by 6 percent moving from A1 to A2, and 5 percent from A3 to A2. These values suggest smaller forest technology rate than were considered in Table 2 . To reach optimal result (30\%) or Finnish government's target $(50 \%)$ of green electricity production, peat should also be replaced by forest fuels. While the principal point is the same, the percentages may differ in different local systems and countries.

Including a decreased purchase rate of the electricity from Russia and Sweden affected the levels of green electricity production (Figure 6). In scenario A2 the optimum electricity purchase level (5205 GWh) should increase production by 7 551GWh. However, for the 12 monthly planning periods, the total increase of green electricity did not occur. Actually, CHP plant procured also more peat. It should be noted that the relative levels of heat production in the scenarios were constant for the 12-month planning horizon. Therefore, results reveal that larger green electricity production did not resulted only from the feed-in tariff $(+6.9 € / M W h)$. There are also transaction costs of wood procurement and CHP production in Finland, which affect profitability of green electricity production [9] [10]. Remarkable changes in the levels of the green electricity production can be seen throughout the year in the solutions of scenarios A1 and A2. Figure 6 shows that continuing to around June, the electricity production patterns were nearly identical for all three scenarios, but starting in around July the differences between scenarios were larger. It seems that during cold months of a year it is easier to stabilize electricity production, while forest fuels are used in the electricity production.

Discussions with the manager of the CHP plant indicated that the differences revealed by the optimal solutions for the three scenarios were within the range of electricity delivery targets that are currently being discussed by the plant managers [10] [13] [22]. Therefore, the remainder of discussions concentrates on differences in green electricity sales, although fossil electricity was also delivered to the grid. Whether the CHP plant sells electricity in given electricity market will depend on the net economic benefits [9]: sales will increase when the plant can produce electricity for a lower cost than the market price. Figure 7 confirms that the green electricity 


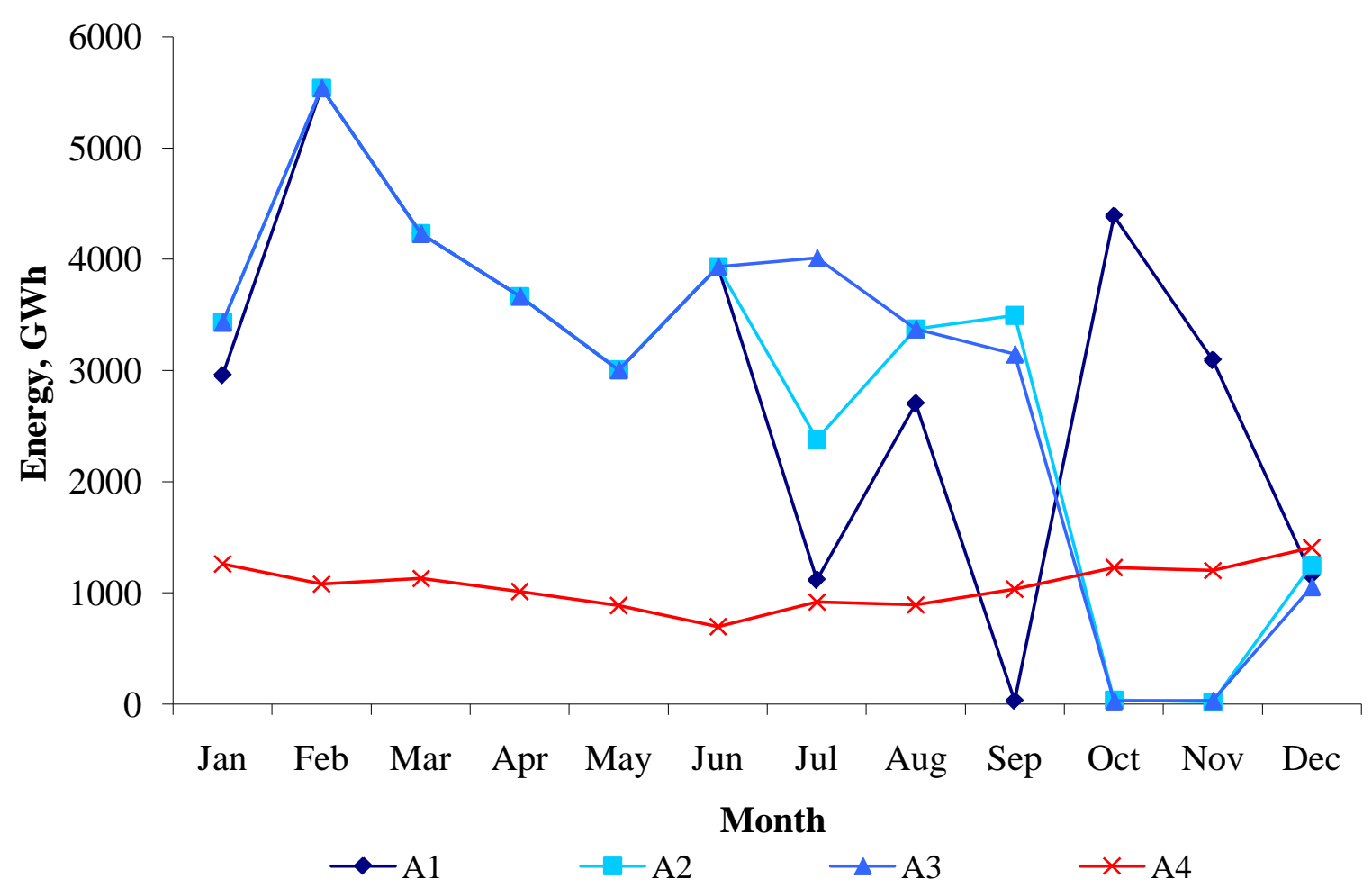

Figure 6. Green electricity production schedules: A1, A2, and A3, which include yearly electricity import purchase rates of 0 percent, 41 percent $(5205 \mathrm{GWh})$, and 100 percent $(12,756 \mathrm{GWh})$, respectively. A4 = Monthly electricity import by 2014 $(12,756 \mathrm{GWh} /$ year $)$.

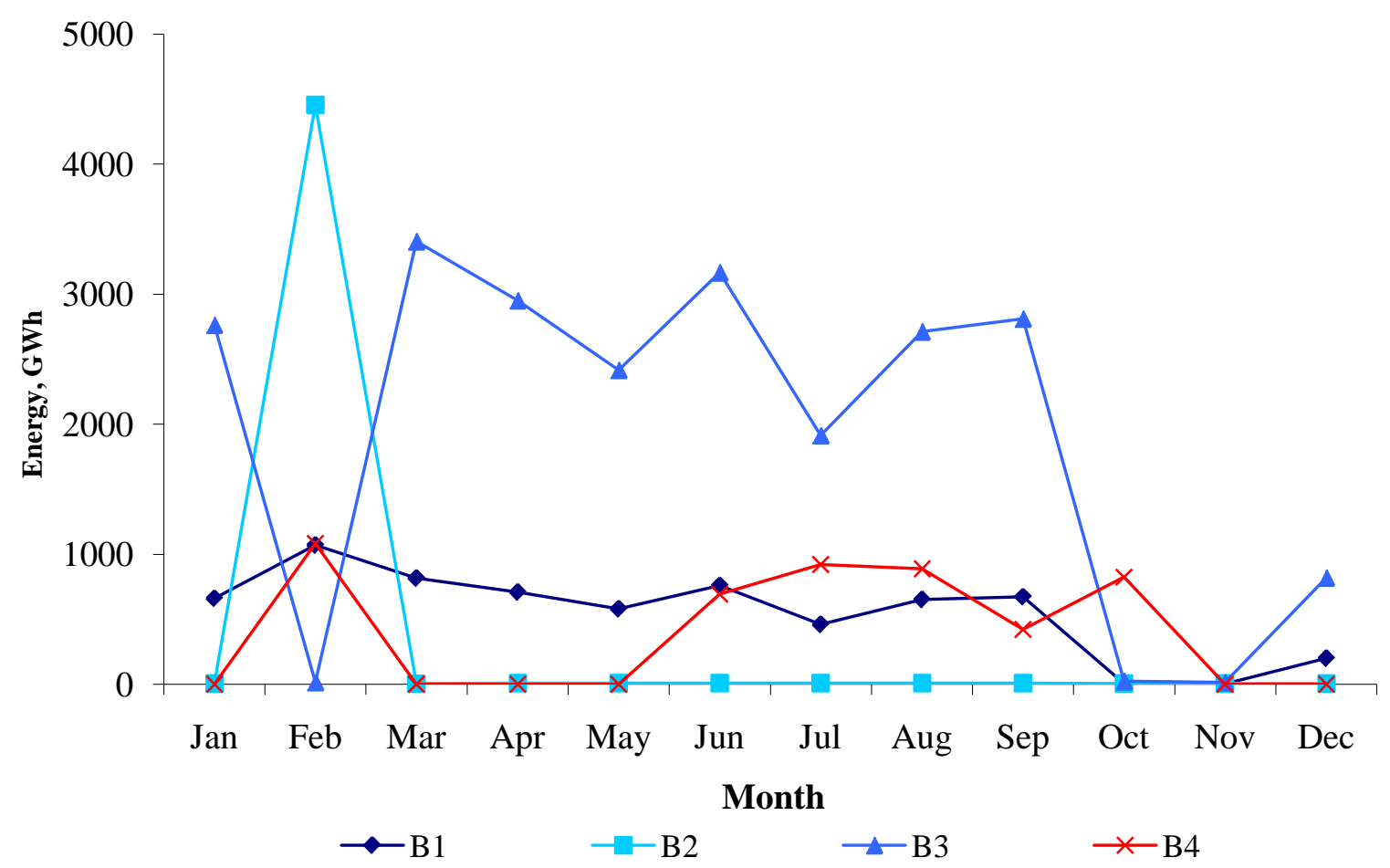

Figure 7. Green electricity sales in Finnish grid which include yearly purchase rate of 41 percent (5205 GWh/year, Scenario A2) for electricity import from Russia and Sweden: B1, B2, B3, B4 are electricity consumption of CHP plants, Households, Forest industry and electricity import, respectively. 
sales into the electrical grid can be scheduled consistently by smart solution methodology [24]. However, remarkable changes in the fluctuating green electricity sales can also be seen throughout the year. As already discussed, the differences between the scheduled electricity sales as a result of including too low purchase rate of imported electricity (scenario A1) could increase purchase rate of fossil fuels and cause stabilization problems in green electricity production. Therefore, the results of this study suggest that the feed-in tariff and energy import targets may not be adequate measures for balancing the electricity production from renewable forest sources. The most important proposals of this study for improvement the decision support systems are the forest technology rates of the wood procurement machinery, which were successfully used for a decision support to solve local forest fuel procurement problem. Additional research will be useful to implement for revealing the effects of energy fuel mixtures and energy efficiency. The decision support will also be further developed to consider grid losses more accurately, and thereby increase the efficiency of the smart solution methodology.

A number of studies have come to conclusion that along with raising the share of fluctuating renewable electricity production, it becomes essential to involve flexible technologies, such as CHP, in grid stabilization tasks [3]-[6]. We used the local forest technology rate of procurement machinery for electricity production stabilization task of CHP. The first automatic attempt to secure and maintain voltage and frequency in the electricity supply has been implemented on the NordPool market in Scandinavia [26]. In the NordPool system CHP combustion engines are used to balance electricity supply at the operational planning level. In this study, the smart energy system automatically integrated CHP's forest fuel procurement with the national electricity sector at the strategic planning level. According to studies [6] [27], the smart energy systems identify synergies between grids in order to achieve an optimal solution for them. Here, such a future system found dynamic synergies between the fuel procurement network (grid) from local forests to a CHP plant (thermal and electric grid) and to Finnish national electrical grid. In order to be able to properly integrate the forest fuel procurement network into the smart energy system, the implementation of the decision-support system has to apply a smart dynamic multiple-objective optimization methodology.

\section{Conclusions}

In this study, the smart solution methodology was developed and tested based on local real-life data from CHP plant. Illustrative strategic scenarios were compared for increasing consumption of renewable forest fuels based on Finland's plans to decrease the import of Swedish and Russian electricity. An increase in the forest technology rate of wood procurement machinery clearly affected the profitability of the green electricity production in the optimal solution of the best scenario. We applied a multiple criteria analysis and a dynamic multiple-objective model for collaboration between forest fuel procurement and electricity production decision makers. The strategic decisions were automatically adjusted to the changed decision environment using the smart solution methodology. Furthermore, the decisions could be made on the basis of comprehensive techno-economic analyses. In this respect, the results illustrate the potential advantages of the smart system and the potential impacts of decentralized electricity production for the Finnish energy sector. The future electricity production decisions should be made accounting for the forest technology rate in a local wood procurement environment. The following advantages of the methodology were observed, but further studies will be needed to demonstrate them for managers in various environments:

- Energy flows from forest to Finnish electrical grid can be adjusted to various decision-making environments using smart solution methodology.

- The methodology can be used as a powerful core of a decision support system and has great potential for the significant improvement in energy-fuel procurement, electricity production and market.

- Smart system generates global optimal solution for a green electricity production within a reasonable computational time.

- Smart system saves costs in practice, because the strategic plan can be automatically distributed to CHP plants.

\section{References}

[1] Ericsson, K. and Nilsson, L.J. (2006) Assessment of Potential Biomass Supply in Europe Using a Resource-Focused Approach. Biomass Bioenergy, 30, 1-15. http://dx.doi.org/10.1016/j.biombioe.2005.09.001

[2] Palander, T. and Vesa, L. (2009) Integrated Procurement Planning for Supplying Energy Plant with Forest, Fossil, and 
Wood Waste Fuels. Biosystems Engineering, 103, 409-416. http://dx.doi.org/10.1016/j.biosystemseng.2009.05.008

[3] Lund, H. and Andersen, A.N., Østergaard, P.A., Mathiesen, B.V. and Connolly, D. (2012) From Electricity Smart Grids to Smart Energy Systems-A Market Operation Based Approach and Understanding. Energy, 42, 96-102. http://dx.doi.org/10.1016/j.energy.2012.04.003

[4] Lund, H., Möller, B., Mathiesen, B.V. and Dyrelund, A. (2010) The Role of District Heating in Future Renewable Energy Systems. Energy, 35, 1381-1390. http://dx.doi.org/10.1016/j.energy.2009.11.023

[5] Münster, M., Morthorst, P.E., Larsen, H.V., Bregnbæk, L., Werling, J. and Lindboe, H.H. (2012) The Role of District Heating in the Future Danish Energy System. Energy, 48, 47-55. http://dx.doi.org/10.1016/j.energy.2012.06.011

[6] Lund, H., Werner, S., Wiltshire, R., Svendsen, S., Thorsen, J.E., Hvelplund, F. and Mathiesen, B.V. (2014) 4th Generation District Heating (4GDH) Integrating Smart Thermal Grids into Future Sustainable Energy Systems. Energy, 68, 1-11. http://dx.doi.org/10.1016/j.energy.2014.02.089

[7] Commission of European Communities (2010) Directive of the European Parliament and of the Council on the Promotion of the Use of Energy from Renewable Sources, Brussel.

[8] Finnish Ministry of Agriculture and Forestry (2008) Finland's National Forest Programme 2015. More Welfare from Diverse Forests, Helsinki.

[9] Palander, T. (2011) Technical and Economic Analysis of Electricity Generation from Forest, Fossil, and Wood Waste Fuels in a Finnish Heating Plant. Energy, 36, 579-590. http://dx.doi.org/10.1016/j.energy.2011.07.014

[10] Palander, T. (2011) Modelling Renewable Supply Chain for Electricity Generation with Forest, Fossil, and Wood Waste Fuels. Energy, 36, 5984-5993. http://dx.doi.org/10.1016/j.energy.2011.08.017

[11] Torvelainen, J., Ylitalo, E. and Nouro, P. (2014) Wood Consumption in Energy Generation in the Year 2013. Metsätilastotiedote.

[12] Palander, T. (1998) Tactical Models of Wood-Procurement Teams for Geographically Decentralized Group Decision-making. Ph.D. Thesis, University of Eastern Finland, Joensuu.

[13] Vehviläinen, I., Hiltunen, J. and Vanhanen, J. (2007) Potential of CHP Production in Cooling and Heating in Finland.

[14] Pöyry Management Consulting (2010) Effects of Heat Tax Changes on Competiveness and Emissions of Gas Fuel in Energy Production in Case Studies, Helsinki.

[15] Promotion of Renewable Energy Production (2010) Valtiontalouden Tarkastusviraston Tuloksellisuustarkastuskertomukset 213. https://www.vtv.fi/files/2397/2132010_Uusiutuvien_energiamuotojen_edistaminen_netti.pdf

[16] Finnish Ministry of Employment and the Economy (2010) CHP Plants’ Feed-In Tariff and Energy Subsidies, Helsinki.

[17] Palander, T., Toivonen, M. and Laukkanen, S. (2002) GroupWare and Group Decision Support Systems for Wood Procurement Organisation. A Review. Silva Fennica, 36, 585-600. http://dx.doi.org/10.14214/sf.546

[18] Zeleny, M. (1982) Multiple Criteria Decision-Making. McGraw-Hill, New York.

[19] Dyer, J., Fishburn, P., Steuer, R., Wallenius, J. and Zionts, S. (1992) Multiple Criteria Decision-Making, Multiattribute Utility Theory—The Next Ten Years. Management Science, 38, 645-654. http://dx.doi.org/10.1287/mnsc.38.5.645

[20] Hämäläinen, R.P. and Mäntysaari, J. (2002) Dynamic Multi-Objective Heating Optimization. European Journal of Operational Research, 42, 1-15. http://dx.doi.org/10.1016/S0377-2217(01)00282-X

[21] Hämäläinen, R.P., Mäntysaari, J., Ruusunen, J. and Pineau, P.O. (2000) Cooperative Consumers in a Deregulated Electricity Market—Dynamic Consumption Strategies and Price Coordination. Energy, 25, 857-875. http://dx.doi.org/10.1016/S0360-5442(00)00024-4

[22] Palander, T.S. and Hietanen, A. (2014) Optimisation of Renewable Forest Fuel Supply for More Sustainable Energy Production of CHP Plant in Finland. International Journal of Environment and Sustainable Development, 13, 20-33. http://dx.doi.org/10.1504/IJESD.2014.056411

[23] Finnish Ministry of Agriculture and Forestry (2005) Finland's National Strategy for Climate Change. Helsinki.

[24] Fingrid (2015). http://www.fingrid.fi/en/Pages/default.aspx

[25] Taha, H.A. (2010) Operations Research: An Introduction. 9th Edition, Prentice Hall, New York.

[26] Järventausta, P., Verho, P., Partanen, J. and Kronman, M. (2011) Finnish Smart Grids—A Migration from Version One to the Next Generation. 21st International Conference and Exhibition on Electricity Distribution, Frankfurt am Main, 6-9 June 2011, 1-4.

[27] Jiang, X.S., Jing, Z.X., Li, Y.Z., Wu, Q.H. and Tang, W.H. (2014) Modeling and Operation Optimization of an Integrated Energy Based Direct District Water-Heating System. Energy, 64, 375-388. http://dx.doi.org/10.1016/j.energy.2013.10.067 